Article

\title{
Characteristics of Cyberstalking Behavior, Consequences, and Coping Strategies: A Cross- Sectional Study in a Sample of Italian University Students
}

\author{
Tatiana Begotti and Daniela Acquadro Maran * (D) \\ Department of Psychology, Università di Torino, Via Verdi 10, 10124 Torino, Italy; tatiana.begotti@unito.it \\ * Correspondence: daniela.acquadro@unito.it; Tel.: +39-011-6702262
}

Received: 8 April 2019; Accepted: 22 May 2019; Published: 22 May 2019

\begin{abstract}
Aims: The aim of this study was to compare victims of one type of cyberstalking (OneType) with victims of more than one type of cyberstalking (MoreType) regarding (1) the impact of cyberstalking and (2) attitudes related to telling someone about the experience of cyberstalking and the coping strategies used by victims. Methods: A self-administered questionnaire was distributed to over 250 students at the University of Torino. Results: About half of the participants experienced at least one incident of cyberstalking. Among them, more than half experienced more than one type of cyberstalking. Victims suffered from depression more than those who had never experienced cyberstalking. No statistically significant difference emerged for anxiety. The coping strategies used by MoreType were more varied than those used by OneType victims of cyberstalking. Moreover, MoreType victims told someone about their victimization more than OneType victims. Conclusion: The work presented suggests implications for health care professionals, police officers, and government. For example, our suggestion is to pay attention to cyberstalking victims and provide flyers in schools, universities, and cafeterias that explain the risk of certain online behaviors and their consequences in physical and emotional spheres.
\end{abstract}

Keywords: cyberstalking; anxiety; depression; online harassment; victims

\section{Introduction}

Cyberstalking has been defined by Spitzberg and Hoobler [1] as the use of the Internet and email or other electronic communication devices to repetitively harass another person with the intent to control, coerce, intimidate, annoy, or threaten them. The motive that determines the beginning of cyberstalking behavior differs from other forms of misconduct. For example, cyberharassment is a more general term that refers to the involvement of engaging in an act to torment, terrorize, or offend an individual online with the intention of harming that person [2]. As a consequence of cyberstalking, victims experience a continual state of anxiety or fear that affects their quality of life and could force them to change their online and offline habits [3,4]. Other authors such as Goodno [5] and Nobles, Reyns, Fox, and Fisher [6] underscored the fact that cyberstalking permits the instant harassment of victims by being far from the victim and maintaining anonymity, impersonating others (including the same victim), and encouraging third parties to take part in the cyberstalking behavior.

Similar to research on the stalking phenomenon, several studies have been conducted into the prevalence of cyberstalking, the nature of the relationship between the protagonists, the characteristics of the behavior, the consequences of victimization, and the coping strategies adopted by victims. Due to the nature of the motives for using the Internet and social networks (e.g., searching for new friends) [7], young people are more likely to become victims of cyberstalking than other violent and 
repetitive phenomena. The victimization seems to decrease with age, while the likelihood of reporting stalking victimization tends to increase [8]. For example, findings from Spitzberg and Hoobler's [1] investigation showed that almost one-third of 235 undergraduate college students reported some form of unwanted online pursuit. Moreover, findings from Paullet, Rota, and Swan's [9] investigation showed that $13 \%$ of 302 undergraduate and graduate students were victims of cyberstalking. D'Ovidio and Doyle [10] analyzed cyberstalking cases reported to police. The perpetrator was male in $80 \%$ of the cases and the average age was 24 , whereas the victim was a female in $52 \%$ of the cases and the average age was 32. Similarly, Kraft and Wang [11] found that victims of cyberstalking were younger than the rest of the sample. The reason for this seems to be linked to confidence in the online space; young adults do not exercise the caution communicating online with unknown people that they would in a face-to-face interaction [12]. Moreover, they post a large amount of personal information without thinking about the consequences [13]. They allow themselves to be vulnerable to cyberstalking by giving information online about themselves (last name, cell phone number, address) as well as about their relatives, friends, interests, favorite places, and other information. They do not exercise the same caution when communicating with strangers online as they would in person [14].

In an interesting finding about the victim-cyberstalker relationship, Cavezza and McEwan [15] underscored the conclusion that the cyberstalker, like the stalker, is in most cases an ex-intimate partner. However, Reyns, Henson, and Fisher [16], in their investigation involving 355 victims of cyberstalking, showed that most cyberstalkers were strangers (42.5\%). An intimate cyberstalker was indicated by $21.7 \%$ of participants, whereas the rest indicated a friend/acquaintance as the cyberstalker. The behaviors adopted by cyberstalkers are varied. Reyns and colleagues [16], in their investigation, underscored the finding that victims on average experienced 2.95 different types of behaviors. Similarly, Montiel, Carbonell, and Pereda [17] found that the majority of cyberstalking victims experienced multiple behaviors-on average, 1.40. These behaviors could be harassment, identity fraud, threat of violence, unwanted sexual advances, or unwanted contact. Those findings were not confirmed by D'Ovidio and Doyle [10]. In their investigation, they found that, in most cases, unwanted contact (by email) was the cyberstalker's behavior. The discrepancies between prior studies are probably due to different methodological approaches. These differences stress the need to deepen the subject by going into more detail. As with stalking, cyberstalking causes physical and emotional consequences in victims, including stomach trouble, sleep disorders, anger, fear, confusion $[4,6]$, distress, anxiety, and depression. Those consequences affect the victims' mental health and well-being.

To cope with this phenomenon, victims adopt strategies to stop the perpetrator (e.g., avoidant coping, ignoring the perpetrator, seeking support) and/or change their daily online routine (e.g., avoid a certain chat room or change their Facebook status). There is a gap in the literature about the consequences and coping strategies adopted by victims who experienced only one type of online harassment behavior and those who experienced multiple online harassment behaviors. As in other forms of violence, a behavior characterized by more than one conduct implies different strategies, is more expensive for the victims, and causes more consequences [18,19].

The first aim of this study was to analyze the impact of cyberstalking (in terms of physical and emotional symptoms, depression, and anxiety) on subjects who had been victims of one type of cyberstalking, comparing them with those who were victims of more than one type of cyberstalking. To better understand the impact of the cyberstalking behavior, a comparison was also made (for anxiety and depression) with those who had never experienced this type of victimization. The second aim was to analyze attitudes related to telling someone about the experience of cyberstalking and the coping strategies used by victims, comparing subjects who had been victims of one type of cyberstalking with those who were victims of more than one type. The target population was young adults because, as suggested by Dreßing, Bailer, Anders, Wagner and Gallas [20], they are more at risk of cyberstalking victimization than other individuals. The hypotheses were as follows: 
i Cyberstalking behavior had an impact on victims' well-being by increasing physical and emotional symptoms, anxiety, and depression;

ii Those symptoms increased especially in victims who experienced more than one type of cyberstalking;

iii Victims who experienced more than one type of cyberstalking were more prone to use a variety of coping strategies.

\section{Results}

\subsection{Demographic Details about Victims of Cyberstalking}

Less than half of the participants (111, $48.5 \%$ ) had been victims of stalking ( $61 \%$ females; mean age $=22.7, \mathrm{SD}=1.97)$. Within the total sample, $49(21.4 \%)$ had been victims of one type of stalking and $62(27.1 \%)$ had been victims of more than one type of stalking. The majority of cyberstalking victims were single $(65 \%), 27.5 \%$ were engaged, and $2.8 \%$ were cohabiting. The remaining portion did not answer the question. To facilitate reading, from this point in the text onwards, we use the abbreviation "OneType" to indicate those subjects who were victims of one type of cyberstalking and "MoreType" to indicate victims of more than one type of cyberstalking. The participants who never experienced a cyberstalking behavior were indicated with the word "Never".

\subsection{The Cyberstalking Behaviour}

Online contact. Of the participants, 65 (28.4\%) indicated having suffered cyberstalking through online contacts. Most of the victims were females (73.4\%) and, for most of them, the stalker was a man (73.5\%). He was a friend or acquaintance in $53.8 \%$ of the cases and a partner or ex-partner $(20 \%)$ or a stranger $(26.2 \%)$ in the remaining cases. For 24 subjects $(85.9 \%)$, the stalking behavior using online contact had already ended.

Online harassment. Of the participants, 44 (19.3\%) indicated having suffered stalking through online harassment. Victims were females in $52.3 \%$ of the cases and, for most of the victims, the stalker was a man $(67.6 \%)$. He was a friend or acquaintance in $60.4 \%$ of the cases and a partner or ex-partner $(16.3 \%)$ or a stranger $(23.3 \%)$ in the remaining cases. For 38 subjects $(88.4 \%)$, the stalking behavior through online harassment had already ended.

Unwanted sexual advances online. Of the participants, $46(20.2 \%)$ indicated having suffered stalking through unwanted sexual advances online. Most of the victims were females $(73.9 \%)$ and, for most of them, the stalker was a man (86.7\%). He was a friend or acquaintance in $60.9 \%$ of the cases and a partner or ex-partner (4.3\%) or a stranger (34.8\%) in the remaining cases. For 40 subjects $(87 \%)$, the stalking behavior using unwanted sexual advances online had already ended.

Online threats of violence. Of the participants, 27 (11.8\%) indicated having suffered stalking through online threats of violence. In $53.8 \%$ of the cases, the victims were males and, in $57.1 \%$ of the cases, the stalker was a man. He was a friend or acquaintance in $66.7 \%$ of the cases and a partner or ex-partner $(11.1 \%)$ or a stranger $(22.2 \%)$ in the remaining cases. For 24 subjects $(92.3 \%)$, the stalking behavior using online threats of violence had already ended.

Online identity fraud. Of the participants, $28(12.2 \%)$ indicated having suffered stalking through online identity fraud. In $53.6 \%$ of the cases, the victims were females and, in $66.7 \%$ of the cases, the stalker was a man. He was a friend or acquaintance in $32.1 \%$ of the cases and a partner or ex-partner $(10.7 \%)$ or a stranger $(57.1 \%)$ in the remaining cases. For 21 subjects $(75 \%)$, the stalking behavior using online identity fraud had ended.

\subsection{Physical and Emotional Symptoms}

The victims reported various consequences connected to their cyberstalking experience. Physical and emotional symptoms are reported in Table 1, which distinguishes between subjects who were 
victims of one type of cyberstalking (OneType; $n=49$ ) and those who were victims of more than one type (MoreType; $n=62$ ). Only victims of cyberstalking responded to these questions.

Table 1. Physical and emotional symptoms: comparison between OneType and MoreType (percentage in brackets) victims. $\chi^{2}=$ chi-square value; n.s. $=$ not statistically significant: $\varphi=$ phi value

\begin{tabular}{lccccc}
\hline & OneType $(n=49)$ & MoreType $(\boldsymbol{n = 6 2 )}$ & $\chi^{\mathbf{2}}$ & $p$ & $\boldsymbol{p}$ \\
\hline Physical Symptoms & & & & & \\
\hline Weight change & $3(7.3)$ & $9(15.3)$ & 1.44 & n.s. & 0.120 \\
Appetite trouble & $2(4.9)$ & $15(25.4)$ & 7.24 & 0.006 & 0.269 \\
Sleep disorders & $5(12.2)$ & $22(37.3)$ & 7.73 & 0.004 & 0.278 \\
Headache & $6(14.6)$ & $12(20.3)$ & 0.53 & n.s. & 0.073 \\
Tiredness & $6(14.6)$ & $7(28.8)$ & 2.75 & n.s. & 0.166 \\
Nausea & $5(12.2)$ & $9(15.3)$ & 0.19 & n.s. & 0.043 \\
Weakness & $5(12.2)$ & $10(16.9)$ & 0.43 & n.s. & 0.065 \\
Self-inflicted harm & - & $1(1.7)$ & 0.70 & n.s. & 0.084 \\
Laxative use & - & $1(1.7)$ & 0.70 & n.s. & 0.084 \\
Forced vomiting & - & $2(3.4)$ & 1.42 & n.s. & 0.119 \\
Being hurt by stalker & - & $2(3.4)$ & 1.42 & n.s. & 0.119 \\
Panic attack & $5(12.2)$ & $13(22.4)$ & 2.51 & n.s. & 0.159 \\
\hline Emotional Symptoms & & & & & \\
\hline Suicidal thoughts & $2(4.9)$ & $2(3.4)$ & 0.14 & n.s. & -0.037 \\
Sadness & $12(29.3)$ & $33(55.9)$ & 6.95 & 0.007 & 0.264 \\
Anger & $23(56.1)$ & $40(67.8)$ & 1.42 & n.s. & 0.119 \\
Confusion & $14(35.0)$ & $33(55.9)$ & 4.19 & 0.032 & 0.206 \\
Fear & $11(26.8)$ & $26(44.1)$ & 3.08 & n.s. & 0.176 \\
Lack of confidence in others & $8(19.5)$ & $17(28.8)$ & 1.12 & n.s. & 0.106 \\
Aggressiveness & $6(14.6)$ & $19(32.2)$ & 3.98 & 0.037 & 0.200 \\
Paranoia & $9(22.0)$ & $26(44.1)$ & 5.20 & 0.018 & 0.228 \\
Irritation & $20(48.8)$ & $35(59.3)$ & 1.09 & n.s. & 0.104 \\
Agoraphobia & $1(2.4)$ & $6(10.2)$ & 2.22 & n.s. & 0.149 \\
\hline
\end{tabular}

The total percentage can be over 100 because every subject could choose more than one consequence. In general, the results showed more consequences for MoreType victims. In particular, concerning physical symptoms, they suffered more appetite trouble and sleep disorders. For emotional symptoms, they suffered more sadness, confusion, aggressiveness, and paranoia.

\subsection{Depression and Anxiety Symptoms}

Overall, the findings showed that 133 subjects in the sample (58.1\%) had a minimal score for depression symptoms. The rest of the sample had a mild score $(35,15.3 \%)$, a moderate score $(26$, $11.4 \%)$, or a severe score $(6,2.6 \%)$ on the Beck Depression Inventory (BDI). In the case of state anxiety symptoms, 98 subjects (42.8\%) scored under 40 (the threshold value considered predictive of state anxiety symptoms). Of the participants, 70 (30.6\%) had mild anxiety, 33 (14.4\%) had moderate anxiety, and the rest $(12.2 \%)$ had severe anxiety. For trait anxiety symptoms, 88 subjects (38.4\%) scored under 40. Of the participants, $79(34.5 \%)$ had a mild score, $40(17.5 \%)$ had a moderate score, and the rest $(9.6 \%)$ had a severe trait anxiety score.

One-way ANOVA analyses were performed to compare subjects who were never involved in a cyberstalking behavior (Never; $n=118$ ) with those who had been victims of one type (OneType; $n=49$ ) or more than one type of cyberstalking (MoreType; $n=62$ ). The BDI, State-Trait Anxiety Inventory version 1 (STAIY1) and STAIY2 scales were introduced as dependent variables. A Tukey post-hoc test was used. Results are reported in Table 2. Significantly different means are indicated with different letters at the apex. 
Table 2. Depression and anxiety symptoms: comparison between Never, OneType, and MoreType (one-way ANOVA) victims. Notes: M, mean; SD, standard deviation; F, Fisher's ratio; n.s., not statistically significant. Significantly different means are indicated with different superscript letters.

\begin{tabular}{|c|c|c|c|c|c|c|}
\hline & $\begin{array}{l}\text { Never } \\
(n=118) \\
M(S D)\end{array}$ & $\begin{array}{l}\text { OneType } \\
(n=49) \\
\text { M (SD) }\end{array}$ & $\begin{array}{c}\text { MoreType } \\
(n=62) \\
\text { M (SD) }\end{array}$ & $F$ & $p$ & $\eta^{2}$ \\
\hline $\begin{array}{l}\text { Depression symptoms } \\
\text { (Range: 0-39) }\end{array}$ & $3.00^{\mathrm{a}}(3.324)$ & $3.98^{a b}(3.822)$ & $5.56^{b}(5.348)$ & 7.004 & $<0.001$ & 0.073 \\
\hline $\begin{array}{l}\text { Anxiety symptoms: } \\
\text { state inventory } \\
\text { (Range: } 20-80 \text { ) }\end{array}$ & $40.90(11.700)$ & $40.62(10.620)$ & $43.03(10.856)$ & 0.828 & n.s. & 0.008 \\
\hline $\begin{array}{l}\text { Anxiety symptoms: } \\
\text { trait inventory } \\
\text { (Range: } 20-80 \text { ) }\end{array}$ & 42.04 (10.959) & $43.00(10.811)$ & $45.03(9.875)$ & 1.524 & n.s. & 0.014 \\
\hline
\end{tabular}

As we can see in Table 2, the mean of depressive symptoms was significantly higher in victims of more than one type of cyberstalking compared to those who were not victims. No significant differences were found for anxiety symptoms.

\subsection{Telling Someone and Coping Strategies}

Most of the victims of cyberstalking indicated that they told someone about their experience, with a statistically significant difference between OneType $(27 ; 65.9 \%)$ and MoreType $(49 ; 83.1 \%)$ $\left(\chi^{2}=3.92 ; p=0.041 ; \varphi=0.198\right)$ groups. No statistically significant differences were found regarding people to whom they disclosed their victimization (police, parents/family, friends, partner, physician, and psychotherapist). The victims indicated using various coping strategies (see Table 3 ).

Table 3. Coping strategies: comparison between OneType and MoreType (percentage in brackets) victims. Note: $\chi^{2}=$ chi-square value; n.s. $=$ not statistically significant, $\varphi=$ phi value.

\begin{tabular}{lccccc}
\hline & $\begin{array}{c}\text { OneType } \\
(\boldsymbol{n}=\mathbf{4 9 )}\end{array}$ & $\begin{array}{c}\text { MoreType } \\
(\boldsymbol{n = 6 2 )}\end{array}$ & $\chi^{\mathbf{2}}$ & $\boldsymbol{p}$ & $\boldsymbol{\varphi}$ \\
\hline Collect evidence & $11(25.6)$ & $25(41.0)$ & 2.64 & n.s. & 0.159 \\
Decrease use of Internet & $6(14.3)$ & $20(32.8)$ & 4.51 & 0.027 & 0.209 \\
Have a safety plan & - & $2(3.3)$ & 1.43 & n.s. & 0.118 \\
Increase social contact & $9(21.4)$ & $15(24.6)$ & 0.14 & n.s. & 0.037 \\
Increase misuse of alcohol & $1(2.4)$ & $9(14.8)$ & 4.34 & 0.035 & 0.205 \\
Increase use of drugs & $1(2.4)$ & $2(3.3)$ & 0.07 & n.s. & 0.026 \\
Decrease social contact & $1(2.4)$ & $4(6.6)$ & 0.94 & n.s. & 0.095 \\
Increase use of psychotropic substances & $1(2.4)$ & $4(6.6)$ & 0.94 & n.s. & 0.095 \\
Buy a weapon & - & $5(8.2)$ & 3.62 & n.s. & 0.187 \\
Try to reason with cyberstalker & $5(11.9)$ & $20(32.8)$ & 5.90 & 0.012 & 0.239 \\
Stop the online contact & $24(57.1)$ & $48(78.7)$ & 5.49 & 0.017 & 0.231 \\
Ask for an intervention by a social network administrator & $5(11.9)$ & $17(28.3)$ & 3.94 & 0.039 & 0.197 \\
Ask for an intervention by a phone administrator & - & $4(6.6)$ & 2.91 & n.s. & 0.169 \\
\hline
\end{tabular}

The total percentage can be over 100 because every subject could choose more than one coping strategy.

In general, the most frequent coping strategy was to stop online contact, especially for victims of more than one type of cyberstalking. Compared to OneType victims, MoreType victims also indicated an increase in the misuse of alcohol, of contacting the cyberstalker to ask them to stop the cyberstalking behavior, and of asking for an intervention by a social network administrator.

\section{Discussion}

The aim of this study was to investigate the difference between cyberstalking victims who have experienced one or more than one type of cyberstalking. As suggested by the literature $[1,7,9]$, 
we investigated this phenomenon among young people, who are more prone to use the Internet and social networks to increase social contact, play games, and keep in touch with parents and friends [7]. According to the literature, in our sample, about half of the participants experienced at least one cyberstalking behavior. Among them, more than half experienced more than one type of cyberstalking behavior. Victims showed a higher level of depression than those who had never experienced cyberstalking, with MoreType victims of cyberstalking behaviors reaching the cut-off for mild depression. This finding suggests that MoreType victims need an effective strategy to cope with cyberstalking behaviors. As suggested by the literature, active coping strategies, such as the increase of social contact and the avoidance of the Internet (e.g., to stop the online contact), could be more effective than other methods (e.g., increasing the use of psychotropic substances) [21]. In MoreType victims, the experience causes pessimism, life stress, and emotional reactions that have an impact on the victim's quality of life [22]. For anxiety (both state and trait), no statistically significant difference emerged. Even if the MoreType victims indicated higher levels of anxiety symptoms than other groups, the findings showed that they did not reach the cut-off for mild anxiety symptoms. Thus, hypothesis 1 was only partially confirmed. An interesting finding concerns the consequence of cyberstalking behaviors. As expected, MoreType victims suffered consequences that characterized stalking victims more than OneType victims (hypothesis 2). These findings suggested that, for victims of cyberstalking, there is a need to have the same support offered to stalking victims. For example, it could be useful to conduct an awareness behavior of the risk associated with sharing personal data in an online context, giving information about privacy rights, and what constitutes a crime, such as defamation, threat, and harassment. The findings showed that the coping strategies used by MoreType victims are more varied than those used by OneType victims, confirming hypothesis 3 . This result was in accordance with findings from Spitzberg, Nicastro, and Cousins [23] who argued that "the more a person is obsessively pursued, the more this person attempts to cope, and the increased coping is merely a barometer of the stalking and its disruptiveness, rather than a method of effectively diminishing the negative effects of the stalking" (p. 43). MoreType victims used avoidance strategies, trying to limit access to information or blocking media accessibility. Another strategy used was confrontation with the cyberstalker, asking them about the motives of their behavior and to stop. As suggested by Mullen and Pathe [24], this approach is not an effective strategy in all victimization experiences. With some types of cyberstalkers, this approach could be a counterproductive strategy. According to Davis and Frieze [25], the adoption of an appropriate coping strategy based on the motivation of the cyberstalking behavior (e.g., collecting evidence) could determine the most effective method to stop the stalking behavior [26]. Moreover, MoreType victims were more prone than OneType victims to tell someone about their victimization. Even if no statistically significant difference emerged about the person whom victims asked for help, these data confirmed that MoreType victims experienced fatigue from coping with various repetitive and intrusive behaviors that distressed them [27], leading to exhaustion. The ask for help seems to be a last chance to cope with the phenomenon, as emerged in studies with victims of other types of violence [18].

There were, of course, some limitations to this study. First, since the investigation was cross-sectional and the sample was not randomly selected, the results should be taken with caution and should not be generalized. Moreover, findings showed that the majority of victims were females, while the cyberstalkers were males. The gender of the cyberstalker and the victim was not investigated, as with sexual orientation. Gender and sexual orientation could be one of the reasons for the cyberstalking behavior, that is, the interruption of a relationship, for example, or resentment for a refusal to accept romantic dating. As suggested by Derlega, Winstead, Pearson, Janda, Lewis, Dutton, Ferrer and Greene [28], men are more prone than women to harass and to act repetitively and intrusively to re-establish a relationship. Future research should investigate the impact on men and women who are victims of cyberstalking, the nature of the victim-cyberstalker relationship, and the motives of the cyberstalking behavior as perceived by victims. At least one other limitation was in reference to the perception of violence in online and offline contexts. Many victims did not 
consider the online experience of harassment to be a violent behavior because they perceived that turning off the computer permitted leaving the harassment in cyberspace. As suggested by Worsley, Wheatcroft, Short and Corcoran [29], rumors and harassment could transcend cyberspace and enter daily life. Moreover, underestimating the experience of victimization does not permit recognizing the problem and, as a consequence, asking for help to cope with the phenomenon. We suggest that future studies examine the perception of online and offline violence in victims and non-victims in a more comprehensive way. As argued by White and Carmody [30], the study of these variables could allow a better understanding of the dynamics of the cyberstalking phenomenon and its consequences and an exploration of the coping strategies suggested by victims to interrupt the phenomenon. Another limitation of the survey was that it asked participants if they had ever experienced certain cyberstalking behaviors. Probably, experiencing cyberstalking during childhood is different from adult victimization. Our suggestion is to use a time frame, such as the last five years, in future research to better understand the impact of victimization and re-revictimization experienced during adulthood. Finally, there could be a bias linked to socially desirable responding, that is, the tendency to reply to a questionnaire while giving a favorable image of oneself. In particular, investigation into victimization should ask participants if they had ever cyberstalked; in their investigation, Smith, Mahdavi, Carvalho, Fisher, Russell, and Tippett [31] found that $15 \%$ of the victims of traditional bullying perpetrated cyberbullying. Future research could use the Social Desirability Scale, in association with the other tools used in this investigation, to improve the validity of questionnaire-based research [32].

\section{Materials and Methods}

\subsection{Participants}

A self-administered questionnaire was distributed to over 250 students at the University of Torino, which is situated in a large city in the northwest part of Italy. The questionnaires were filled out by 229 (91.6\%) individuals, of which $116(50.9 \%)$ were females and $113(49.1 \%)$ were males. They were aged from 18 to 27 years $(\mathrm{M}=22.7, \mathrm{SD}=2.31)$. The majority were single $(62.5 \%), 31.3 \%$ were engaged, and $2.7 \%$ were cohabiting (the remaining portion did not answer the question). Respondents took part on a voluntary basis and did not receive any compensation (or extra credit) for their participation.

\subsection{Measures}

The scale developed by Reyns, Henson, and Fisher [16] was used to investigate the prevalence of cyberstalking. Respondents were asked if they experienced any behaviors that characterized a cyberstalking conduct: contact ("Has anyone ever contacted you or attempted to contact you on more than one occasion online after you asked/told them to stop?"), harassment ("Has anyone ever harassed you or attempted to harass you online on more than one occasion?"), unwanted sexual advances ("Has anyone ever made unwanted sexual advances toward you on more than one occasion online?"), threats of violence ("Has anyone ever spoken to you in a violent manner or threatened to physically harm you on more than one occasion online?") or identity fraud ("Has anyone ever pretended to be you online, without your permission?") (possible answers: yes/no). For each type of behavior, participants indicated the victim-perpetrator relationship (possible answers: intimate, friend/acquaintance, stranger).

The questionnaire was adapted for use with an Italian audience by translating it from British English and then back-translating it [33]. The translation was performed by the authors and two research assistants, whose work was expected to match in order to agree on a final version. In addition, five items were added to the original scale to obtain the gender (if known) of the perpetrator and the duration and frequency of the behavior (possible answers: one or more times a day, more than three times a week, once a week, once a month, less than once a month). The questionnaire was already used in a previous investigation on cyberstalking in an Italian audience [34]. 
Regarding consequences and coping strategies, this measure was taken from the Italian version of the Questionnaire on Stalking [4]. In all, 12 items investigated physical symptoms resulting from the cyberstalking experience (e.g., weight change, appetite trouble, sleep disorders; yes/no answers) and 11 items investigated the emotional consequences (e.g., sadness, anger, confusion; yes/no answers). Victims of cyberstalking responded to one question regarding telling someone about their experience ("did you tell someone about your experience?"; yes/no answers). If the answer was yes, they responded to 7 items about people to whom they told their experience (police, parents/family, friends, partner, physician, psychotherapist, others; yes/no answers). Coping strategies were measured through 16 items (e.g., "did you make any plan of action for escape?" yes/no answers), while 7 items investigated their help-seeking (e.g., "did you ask for help from the police?" yes/no answers).

To measure depression and anxiety symptoms, the shortened Beck Depression Inventory (BDI) [35,36] and the State-Trait Anxiety Inventory (STAI) [37,38], respectively, were used. The shortened version of the BDI consists of 13 items [39] that permit the classification of symptoms and attributes according to a level of gravity: none or minimal depression (scores $0-4$ ), mild depression (5-7), moderate depression (8-15), or severe depression (>15) (in this study, Cronbach's $\alpha$ was 0.82). The State-Trait Anxiety Inventory consists of two forms (STAIY1 and STAIY2; 20 items each) used to assess how participants feel "right now", at this moment, and how they feel most of the time (respectively, for state anxiety and trait anxiety). Total scores can range between 20 and 80 , and 40 is the threshold value considered predictive of anxiety symptoms. The rating scale defines the level of severity as follows: from 40 to 50 is mild, 51 to 60 is moderate, and $>60$ is severe. Cronbach's $\alpha$ values were 0.93 and 0.92 , respectively.

Participants were asked to provide some personal details, such as gender, age, education level, marital status, as well as time spent (and motives) on social networks.

\subsection{Procedure}

This research project was approved by the local ethical committee (N.277326/2017). After the approval, two research assistants were properly trained by the researchers to collect the data. The questionnaires were administered to 250 students in cafeterias, in coffee bars, and in dormitories. Each participant received a printout of the questionnaire, the information letter, and the informed consent form, in accordance with the Declaration of Helsinki. The duration of the questionnaire was $20 \mathrm{~min}$ on average. These materials were completed and returned immediately.

In the section dedicated to the aims of the research, cyberstalking was described using the definition by Spitzberg and Hoobler [1] and that by Galeazzi and Curci [40]: "Cyberstalking is a phenomenon that is defined as a set of threatening and/or harassing repeated behaviors aimed at searching, controlling, hacking personal information, and damaging an individual's reputation through the use of online communication tools: e-mail, blog, social network, chat room or other sites. Such undesirable behaviors are perceived by the victim as annoying, unwanted, threatening to their own safety."

\subsection{Data Analysis}

Data were processed using SPSS version 25 (IBM Corp., Armonk, NY, USA). Descriptive and inferential statistics were performed. Descriptive measures (means \pm SD) were calculated for all test variables for each type of victim (one and more type of victimization). $\chi^{2}$ tests were used to measure the differences between one type and more than one type of victimization. The phi value was calculated to estimate the effect size. Data were subjected to an ANOVA, which measured the difference between the groups (one type, more than one type and those who never experienced cyberstalking); the Tukey post-hoc was used for comparison among groups. Eta-squared was calculated to estimate the effect size. Differences were considered statistically significant if $p<0.05$. 


\section{Conclusions}

Despite these limitations, the work presented here offers interesting insights and suggests implications for health care professionals, police officers, and government. First, for health care professionals, our suggestion is to pay attention to cyberstalking victims and provide flyers in schools, universities, and cafeterias, for example, that explain the risk of certain online behaviors and their consequences in physical and emotional spheres. Moreover, flyers could contain information about websites and self-help (T-groups) to aid people afflicted by cyberstalking.

As attention is generally focused on victims of violence and stalking, the phenomenon of cyberstalking could be underestimated by potential victims. Outreach by professionals on this matter could prompt victims to ask for help. At the same time, health care professionals need specific training on how to manage cyberstalking victims, recognize the different behaviors adopted by the cyberstalker, and cultivate more effective coping strategies. Second, police officers are encouraged to intervene to protect victims using legal and information systems to stop intrusive and unwanted contact online [41]. Advertisements on social networks, and in cyberspace more generally, about cyberstalking behavior and who to contact for help could be a deterrent for cyberstalkers and could be supportive for victims. Third, government has to improve the fight against harassment in cyberspace, which includes cyberstalking. The consequences for victims are the same as stalking [42]. Therefore, there is a need to pay attention to this phenomenon. For example, a national plan could be instigated to inform the general population about the risk of online contact, provide strategies to protect privacy, and offer available services to victims (health care professionals, police) and to the cyberstalker. As suggested by Björklund, Häkkänen-Nyholm, Sheridan, and Roberts [43], this behavior could promote the role of third parties, both in the support of victims and in stopping the perpetrator (for example, suggesting to them to ask for help from a psychologist) [44]. The prevention of this phenomenon is urgently required. Findings from this investigation showed that victimization causes consequences that destabilize the subject and cause physical and emotional symptoms that affect the victims' health, especially for victims of more than one type of behavior.

Author Contributions: Conceptualization, T.B. and D.A.M.; data curation, T.B.; formal analysis, T.B.; investigation, T.B. and D.A.M.; methodology, T.B. and D.A.M.; project administration, T.B. and D.A.M.; supervision, T.B. and D.A.M.; writing, T.B. and D.A.M.

Funding: This research received no external funding.

Conflicts of Interest: The authors declare no conflict of interest.

\section{References}

1. Spitzberg, B.H.; Hoobler, G. Cyberstalking and the technologies of interpersonal terrorism. New Media Soc. 2002, 4, 71-92. [CrossRef]

2. Hazelwood, S.D.; Koon-Magnin, S. Cyber stalking and cyber harassment legislation in the United States: A qualitative analysis. Int. J. Cyber Criminol. 2013, 7, 155.

3. Fremouw, W.J.; Westrup, D.; Pennypacker, J. Stalking on campus: The prevalence and strategies for coping with stalking. J. Forensic Sci. 1997, 42, 666-669. [CrossRef] [PubMed]

4. Acquadro Maran, D.; Varetto, A.; Zedda, M.; Franscini, M. Health care professionals as victims of stalking: characteristics of the stalking behavior, consequences, and motivation in Italy. J. Interpers. Violence 2017, 32, 2605-2625. [CrossRef]

5. Goodno, N.H. Cyberstalking, a new crime: Evaluating the effectiveness of current state and federal laws. Mo. Law Rev. 2007, 72, 125.

6. Nobles, M.R.; Reyns, B.W.; Fox, K.A.; Fisher, B.S. Protection against pursuit: A conceptual and empirical comparison of cyberstalking and stalking victimization among a national sample. Justice Q. 2014, 31, 986-1014. [CrossRef]

7. Alexy, E.M.; Burgess, A.W.; Baker, T.; Smoyak, S.A. Perceptions of cyberstalking among college students. Brief Treat. Crisis Interv. 2005, 5, 279. [CrossRef] 
8. Nobles, M.R.; Cramer, R.J.; Zottola, S.A.; Desmarais, S.L.; Gemberling, T.M.; Holley, S.R.; Wright, S. Prevalence rates, reporting, and psychosocial correlates of stalking victimization: Results from a three-sample cross-sectional study. Soc. Psychiatry Psychiatri. Epidemiol. 2018, 53, 1253-1263. [CrossRef] [PubMed]

9. Paullet, K.L.; Rota, D.R.; Swan, T.T. Cyberstalking: An exploratory study of students at a mid-Atlantic university. Issues Inf. Syst. 2009, 10, 640-649.

10. D'Ovidio, R.; Doyle, J. A study on cyberstalking: Understanding investigative hurdles. FBI Law Enforc. Bull. 2003, 72, 10.

11. Kraft, E.; Wang, J. An exploratory study of the cyberbullying and cyberstalking experiences and factors related to victimization of students at a public liberal arts college. Int. J. Technoethics (IJT) 2010, 1, 74-91. [CrossRef]

12. Lyndon, A.; Bonds-Raacke, J.; Cratty, A.D. College students' Facebook stalking of ex-partners. Cyberpsychol. Behav. Soc. Netw. 2011, 14, 711-716. [CrossRef]

13. Caruso, J.B.; Nelson, M.; Ellison, N. The ECAR study of undergraduate students and information technology. 2008. ECAR Research Studies Colorado: EDUCAUSE Center for Applied Research 2008. Available online: https:/library.educause.edu/resources/2008/10/the-ecar-study-of-undergraduate-studentsand-information-technology-2008 (accessed on 25 January 2019).

14. Marcum, C.D.; Higgins, G.E.; Nicholson, J. I'm Watching You: Cyberstalking Behaviors of University Students in Romantic Relationships. Am. J. Crime Justice 2017, 42, 373-388. [CrossRef]

15. Cavezza, C.; McEwan, T.E. Cyberstalking versus off-line stalking in a forensic sample. Psychol. Crime Law 2014, 20, 955-970. [CrossRef]

16. Reyns, B.W.; Henson, B.; Fisher, B.S. Stalking in the twilight zone: Extent of cyberstalking victimization and offending among college students. Deviant Behav. 2012, 33, 1-25. [CrossRef]

17. Montiel, I.; Carbonell, E.; Pereda, N. Multiple online victimization of Spanish adolescents: Results from a community sample. Child Abuse Negl. 2016, 52, 123-134. [CrossRef]

18. Acquadro Maran, D.; Varetto, A. Psychological impact of stalking on male and female health care professional victims of stalking and domestic violence. Front. Psychol. 2018, 9, 321. [CrossRef]

19. Viñas-Racionero, R.; Raghavan, C.; Soria-Verde, M.Á.; Prat-Santaolaria, R. The association between stalking and violence in a sample of Spanish partner violence cases. Int. J. Offender Ther. Comp. Criminal. 2017, 61, 561-581. [CrossRef] [PubMed]

20. Dreßing, H.; Bailer, J.; Anders, A.; Wagner, H.; Gallas, C. Cyberstalking in a large sample of social network users: Prevalence, characteristics, and impact upon victims. Cyberpsychol. Behav. Soc. Netw. 2014, 17, 61-67. [CrossRef] [PubMed]

21. Nguyen, L.K.; Spitzberg, B.H.; Lee, C.M. Coping with obsessive relational intrusion and stalking: The role of social support and coping strategies. Violence Victim. 2012, 27, 414-433. [CrossRef]

22. Southwick, S.; Charney, D. Resilience: The science of Mastering Life's Greatest Challenges; Cambridge University Press: Cambridge, UK, 2018.

23. Spitzberg, B.H.; Nicastro, A.M.; Cousins, A.V. Exploring the interactional phenomenon of stalking and obsessive relational intrusion. Commun. Rep. 1998, 11, 33-47. [CrossRef]

24. Mullen, P.E.; Pathe, M. Stalking. Crime Justice 2002, 29, 273-318. [CrossRef]

25. Davis, K.E.; Frieze, I.H. Research on stalking: What do we know and where do we go? Violence Vict. 2000, 15, 473-487. [CrossRef] [PubMed]

26. Kaplan, A. Being Stalked-An Occupational Hazard? Psychiatr. Times 2006, 23, 1.

27. Davis, K.E.; Coker, A.L.; Sanderson, M. Physical and mental health effects of being stalked for men and women. Violence Vict. 2002, 17, 429. [CrossRef] [PubMed]

28. Derlega, V.J.; Winstead, B.A.; Pearson, M.R.; Janda, L.J.; Lewis, R.J.; Dutton, L.B.; Ferrer, R.; Greene, K. Unwanted pursuit in same-sex relationships: Effects of attachment styles, investment model variables, and sexual minority stressors. Partn. Abuse 2001, 2, 300-322. [CrossRef]

29. Worsley, J.D.; Wheatcroft, J.M.; Short, E.; Corcoran, R. Victims' Voices: Understanding the Emotional Impact of Cyberstalking and Individuals' Coping Responses. Sage Open 2017, 7. [CrossRef]

30. White, W.E.; Carmody, D. Preventing Online Victimization: College Students' Views on Intervention and Prevention. J. Interpers. Violence 2018, 33, 2291-2307. [CrossRef] [PubMed]

31. Smith, P.K.; Mahdavi, J.; Carvalho, M.; Fisher, S.; Russell, S.; Tippett, N. Cyberbullying: Its nature and impact in secondary school pupils. J. Child Psychol. Psychiatry 2008, 49, 376-385. [CrossRef] 
32. Van de Mortel, T.F. Faking it: Social desirability response bias in self-report research. Aust. J. Adv. Nurs. 2008, 25, 40 .

33. White, M.; Elander, G. Translation of an instrument: The US-Nordic Family Dynamics Nursing Research Project. Scand. J. Caring Sci. 1992, 6, 161-164. [CrossRef]

34. Maran, D.A.; Begotti, T. Prevalence of Cyberstalking and Previous Offline Victimization in a Sample of Italian University Students. Soc. Sci. 2019, 8, 30. [CrossRef]

35. Beck, A.T.; Ward, C.; Mendelson, M. Beck Depression Inventory (BDI). Arch. Gen. Psychiatry 1961, 4, 561-571. [CrossRef]

36. Scilligo, P.F. La scala di depressione di Beck [Beck's Depression Inventory]. In Scale Psicologiche [Psychological Scales]; IFREP: Roma, Italy, 1992.

37. Spielberger, C.D. Manual for the State-Trait Anxiety Inventory STAI (form Y) ("Self-Evaluation Questionnaire"); Consulting Psychologists Press: Palo Alto, CA, USA, 1983.

38. Pedrabissi, L.; Santinello, M. Inventario per l'ansia di «Stato» e di «Tratto»: Nuova Versione Italiana dello STAI Forma Y: Manuale [State-Trait Anxiety Inventory: The Italian New Version of STAI Y form]; Organizzazioni Speciali: Firenze, Italy, 1989.

39. Beck, A.T.; Beck, R.W. Screening depressed patients in family practice: A rapid technic. Postgrad. Med. 1972, 52, 81-85. [CrossRef] [PubMed]

40. Galeazzi, G.M.; Curci, P. La sindrome del molestatore assillante (stalking): una rassegna. Giornale Italiano di Psicopatologia 2001, 7, 434-452. (In Italian)

41. Powell, A.; Henry, N. The Potentials and Limitations of Law. In Sexual Violence in a Digital Age; Palgrave Macmillan: London, UK, 2017; pp. 197-236.

42. Ybarra, M.L.; Langhinrichsen-Rohling, J.; Mitchell, K.J. Stalking-like behavior in adolescence: Prevalence, intent, and associated characteristics. Psychol. Violence 2017, 7, 192. [CrossRef]

43. Björklund, K.; Häkkänen-Nyholm, H.; Sheridan, L.; Roberts, K. Coping with stalking among university students. In Perspectives on Stalking: Victims, Perpetrators, and Cyberstalking; Springer Publishing Company: New York, NY, USA, 2015.

44. Zaccagnino, M.; Cussino, M.; Callerame, C.; Civilotti, C.; Fernandez, I. Anorexia nervosa and EMDR: A clinical case. J. EMDR Pract. Res. 2017, 11, 43-53. [CrossRef] 